\title{
POR UMA CIDADE EDUCADORA - IV SEMINÁRIO TEORIAS E PRÁTICAS SOCIAIS COM CRIANÇAS E ADOLESCENTES
}

\author{
Marcos Vinicius Moura e Silva*, Maykell Araújo Carvalho*, Thatiana Aguiar Freire ${ }^{* *}$
}

\section{RESUMO}

O IV Seminário Teorias e Práticas Sociais com Crianças e Adolescentes foi realizado em 2007, no Centro de Práticas Esportivas da Universidade de São Paulo, sendo uma iniciativa do Projeto Esporte Talento (projeto social de educação pelo esporte desenvolvido pela Universidade de São Paulo em parceria com o Instituto Ayrton Senna) e tendo o apoio da Pró-Reitoria de Cultura e Extensão Universitária.

O tema de referência para as práticas e diálogos foi Por uma Cidade Educadora e o evento teve duas grandes etapas: a Semana da Criança e do Adolescente, que compreendeu uma série de oficinas desenvolvidas para crianças, adolescentes e adultos em espaços públicos da região do Butantã durante uma semana, e o seminário propriamente dito, que envolveu mais de cem pessoas e contou com uma mesa de abertura, quatro rodas de diálogo e a apresentação de dezenove relatos.

Como registro do evento, foi feito um DVD com os principais momentos das duas fases citadas. Cada instituição que propôs uma oficina ou apresentou um relato recebeu esse produto.

O tema do evento antecipou e estimulou, principalmente na região do Butantã, as discussões do “X Congresso Internacional de Cidades Educadoras”, realizado em abril de 2008, na cidade de São Paulo.

Palavras-chave: Cidade Educadora. Crianças e adolescentes.

\section{ABSTRACT}

The IV Seminary of Social Theories and Practices with Children and Adolescents was held in 2007, at the Sports Center of the University of São Paulo, being an initiative of the Sport Talent Project (a social project of education through sports developed for the University of São Paulo in partnership with the Ayrton Senna Institute) and having the support of the Pro-Rectory of Culture and Extension. The subject of reference for practical and the dialogues was For an Educator City and the event had two great stages: the the Child and the Adolescent's Week, where a series of workshops were developed for children, adolescents and adults in public spaces at the Butanta neighborhood during one week and; the seminary properly said, that involved more than one hundred people and included on an opening cerimony, four wheels of dialogue and the presentation of nineteen personal experiences.

As a register of the event, a DVD with the main moments of the two cited phases was made. Each institution that proposed a workshop or presented a story received this product.

The subject of the event anticipated and stimulated, mainly in the region of the Butanta, the discussions of the "X International Congress of the Educational Cities", held in April of 2008 in the city of São Paulo.

Key Words: Educator City. Children and adolescents.

* Centro de Práticas Esportivas da USP. Praça 02, Prof. Rubião Meira, 61 - Cidade Universitária - 05508-900 - E-mail: talento@usp.br. **Mestranda da Escola de Educação Física e Esporte da USP. 


\section{INTRODUÇÃO}

Na década de 90, houve uma proliferação de ações do chamado Terceiro Setor (Organizações NãoGovernamentais, Organizações Sociais de Interesse Público). O surgimento do Projeto Esporte Talento (PET) em 1995, fruto de um convênio entre a Universidade de São Paulo e o Instituto Ayrton Senna, desenvolvido nas dependências do Centro de Práticas Esportivas da Universidade de São Paulo, acompanha essa tendência de responsabilidade social adotada por instituições diversas. 0 diferencial do PET está em seu desenvolvimento dentro da Universidade de São Paulo e, portanto, o compromisso de ir além do atendimento direto às crianças e adolescentes. A formação interdisciplinar de universitários e a sistematização e disseminação do conhecimento gerado também são seus objetivos. Em seus planejamentos anuais, a equipe de coordenação do PET procura desenvolver ações estratégicas que integrem seus três grandes objetivos. E uma dessas ações surgiu em 2004, o Seminário Teorias e Práticas Sociais com Crianças e Adolescentes.

O objetivo da realização deste seminário é oferecer um espaço para apresentação de trabalhos acadêmicos e experiências práticas, bem como compartilhar propostas e buscar aperfeiçoá-las nesse processo. Diferentes temas foram abordados durante os anos: em 2004 - Compartilhando experiências e aprendizados; em 2005 - Educação e comunidade; em 2006 - Políticas públicas. Nesse seminário, em 2006, um dos palestrantes questionou sobre a não presença de jovens e familiares no evento, o que levou a organização a refletir e criar uma proposta onde crianças, adolescentes, familiares e a comunidade em geral pudessem estar envolvidos de uma forma prática nas discussões. Surgiu então, a proposta de realizar, em 2007, a Semana da Criança e do Adolescente, como uma semana de atividades que antecederia o seminário e com o mesmo tema gerador: por uma cidade educadora.

Esse tema foi considerado um passo natural em função das questões surgidas nos anos anteriores. Outra motivação foi o "X Congresso Internacional de Cidades Educadoras: construção de cidadania em cidades multiculturais”, que seria realizado em São Paulo, em abril de 2008. Sendo assim, o seminário iniciou essa discussão na região, mesclando uma ação prática e um espaço de reflexão e diálogo de nossas articulações cotidianas e nosso pensar e olhar coletivos.

\section{POR UMA CIDADE EDUCADORA}

O conceito de Cidade Educadora teve seus alicerces lançados através da Carta de Barcelona, em 1990. Segundo essa carta, "a cidade será educadora quando reconhece, exercita e desenvolve, além de suas funções tradicionais (econômica, social, política e de prestação de serviços) uma função educadora, quando assume a intencionalidade e responsabilidade, cujo objetivo seja a formação, promoção e desenvolvimento de todos os seus habitantes, iniciando pelas crianças e os jovens" (AICE, 1990).

Esse conceito de cidade, implica em entender a educação das crianças, jovens e cidadãos em geral, como responsabilidade de todas as instâncias da sociedade - município, associações, instituições culturais - e não apenas das instituições tradicionais - estado, família, escola - (CABEZUDO, 2004).

$\mathrm{Na}$ tentativa de co-responsabilizar-se por essa educação, projetos de educação complementar à escola e programas governamentais voltados à criança e adolescente tem sido muito influenciados por um discurso de "tirar as crianças e adolescentes das ruas e ocupar o tempo dos mesmos".

\footnotetext{
Hoje, não brincar nas ruas é comportamento ensinado às crianças da cidade, devido aos riscos: atropelamento, violência, roubo, assalto ou indução ao uso de drogas. Mesmo ficando em casa, vendo televisão, brincando e aprendendo na internet, ou jogando no computador, essas crianças são prejudicadas, pois recebem mensagens de violência, não se movimentam, tornam-se agressivas e individualistas (OLIVEIRA, 2004).
}

Para Brarda e Ríos (2004), essa visão negativa sobre a rua relaciona-se com o entendimento de que a escola é o único lugar de aprendizagem, uma vez que fora da escola, nas ruas, se produzem "outras práticas”, que ameaçam desorganizar a ordem escolar. Os mesmos autores apontam a necessidade de considerar a complementaridade dos âmbitos e momentos da educação. Portanto, é fundamental considerar o potencial educativo das ruas e dos espaços públicos. Dentro desse contexto, o tema Por uma Cidade Educadora, o formato das atividades da Semana da Criança e do Adolescente e os relatos do IV Seminário Teorias e Práticas Sociais com Crianças e Adolescentes nascem da 
necessidade de refletir sobre essas questões e pensar novas possibilidades de convívio no espaço público (ruas, praças, parques).

A cidade de São Paulo é um grande centro urbano, a maior cidade do Brasil, com uma população superior a 10 (dez) milhões de habitantes. Traz em sua história todas as contradições, dificuldades e potencialidades de uma cidade que cresceu de maneira vertiginosa e sem um planejamento adequado. É, sem dúvida, uma das cidades com maior diversidade cultural, abrigando manifestações das mais diversas origens étnicas, mas também simboliza a desigualdade social do país. Apresenta pontos marcantes de uma cultura voltada para 0 individualismo e a valorização do material e do financeiro, mas também há o contraste da proliferação de ações e iniciativas voltadas à valorização da solidariedade e da cooperação.

O Butantã, a região onde se desenvolveu a experiência, localiza-se na região oeste da cidade. Representa uma das 31 (trinta e uma) subprefeituras, a subdivisão geopolítica da cidade e, por sua vez, é subdivida em 5 (cinco) distritos: Butantã, Morumbi, Vila Sônia, Rio Pequeno e Raposo Tavares. Essa área da cidade é bem diversificada do ponto de vista econômico e social, apresentando pequenos bolsões de regiões economicamente desfavorecidas. Dentro da proposta, isso representa um potencial: a possibilidade de convivência de pessoas de diversas faixas etárias, classes econômicas, étnicas, etc, em espaços públicos.

Outra característica importante da região é o estabelecimento de algumas redes sociais, traduzidas em sua maioria em encontros mensais de instituições em função da região de atuação (por exemplo, Rede Butantã de Entidades e Forças Sociais, Micro-Rede São Remo) ou de um tema comum (por exemplo, Fórum em defesa dos direitos da criança e do adolescente do Butantã, Rede de Educação). Pela característica de cada rede, os encontros produzem parcerias, ações estratégicas, manifestações por escrito ou presenciais, ações diversas junto ao poder público local, etc.

A realização do IV Seminário Teorias e Práticas Sociais com Crianças e Adolescentes e da Semana da Criança e do Adolescente simbolizaram o esforço em promover ações para que os envolvidos se sintam agentes participativos, articuladores e multiplicadores de transformações sociais em ambientes e espaços diversos. Esse objetivo se opõe ao estigma de que "projeto social é bom porque tira crianças da rua" e propõe a possibilidade da transformação gradativa e possível da comunidade em um espaço de convivência e de educação, compreendendo dessa forma um conceito de educação integral que ocorre nos múltiplos espaços sociais e sob responsabilidade de todos os cidadãos.

Isso é plenamente favorável à educação e ao desenvolvimento de todos os envolvidos, principalmente para as crianças e adolescentes, pois o impacto e as oportunidades de desenvolvimento serão muito maiores do que se restritas exclusivamente ao atendimento direto nos espaços formais de educação.

\section{OBJETIVOS}

Os objetivos visados com a Semana da Criança e do Adolescente e o IV Seminário Teorias e Práticas Sociais com Crianças e Adolescentes foram:

- oferecer uma diversidade de atividades para crianças, adolescentes e adultos;

- envolver diversos atores educativos em uma ação em rede, com cada um disponibilizando parte do seu potencial para o alcance de objetivos comuns;

- propor uma lógica de funcionamento diferente da rotina de atendimento das instituições para refletir sobre o processo de institucionalização das crianças e adolescentes;

- promover reflexões sobre as práticas de atendimento de crianças e adolescentes em instituições de educação formal e, principalmente, informal e a articulação dessas práticas com um contexto maior da região/cidade em prol de uma educação efetivamente integral;

- estimular nos participantes da Semana da Criança e do Adolescente: a percepção do espaço público e a apropriação do seu uso, inicialmente mediado pela ação de educadores; a escolha dos temas e dos espaços de interesse diante de oportunidades diversas; o trânsito entre diferentes espaços e a compreensão de como acessá-los no seu dia a dia; a mobilização de outras pessoas para participarem das atividades; o desenvolvimento das competências pessoais, sociais, cognitivas e produtivas propostas em cada atividade; o conhecimento dos temas tratados em cada atividade e a sua relação com direitos e deveres.

\section{METODOLOGIA}

Compreendemos a metodologia como todo o processo de concepção, articulação e desenvolvimento do 
evento. Por isso, a primeira fase correspondeu em formatar a ideia inicial no Planejamento anual do Projeto Esporte Talento, organização responsável pela iniciativa. No início de 2007 foi definido o tema central - Por uma Cidade Educadora - e o formato da semana de atividades e oficinas. Em julho de 2007, durante os acertos de planejamento para o 2 o semestre, foi formada uma comissão interna no Projeto Esporte Talento para desenvolver a proposta.

A segunda fase correspondeu à mobilização dos parceiros. Aproveitando as redes sociais da região, foi feito o convite para a manifestação de interesse em participar da semana através da inscrição de oficinas e/ou do seminário através da inscrição de relatos. As instituições foram chamadas a participar de uma reunião com 0 intuito de oferecer maiores explicações e sensibilizar os interessados a se tornarem co-organizadores da proposta. Com a realização desta reunião, 10 (dez) instituições se prontificaram a oferecer atividades durante a Semana da Criança e do Adolescente e a intenção de apresentação de mais de 20 (vinte) relatos no IV Seminário Teorias e Práticas Sociais com Crianças e Adolescentes também foi manifestada.

A terceira fase correspondeu à definição da programação de atividades e sua posterior divulgação às crianças e adolescentes participantes das instituições envolvidas, mas também para a comunidade como um todo. A programação da Semana da Criança e do Adolescente foi definida de acordo com as possibilidades de horário de cada envolvido, mas também procurando diversificar e manter um número equilibrado de atividades em cada dia da semana. As atividades tiveram como referência de planejamento a promoção do desenvolvimento humano e o Estatuto da Criança e do Adolescente (Lei Federal 8.069, 13 de julho de 1990), que em seu artigo 4o diz que "é dever da família, da comunidade, da sociedade em geral e do poder público assegurar, com absoluta prioridade, a efetivação dos direitos referentes à vida, à saúde, à alimentação, à educação, ao esporte, ao lazer, à profissionalização, à cultura, à dignidade, ao respeito, à liberdade e à convivência familiar e comunitária” (BRASIL, 2002).

Também vieram ao encontro da ideia de Brarda e Ríos (2004) "não é suficiente aprender a se movimentar pela cidade; é preciso também adquirir a possibilidade de poder utilizar todos os recursos e serviços que esta nos oferece".

A divulgação foi feita através da confecção de um convite e de um cartaz que foram reproduzidos e distribuídos para os educandos, para as instituições diretamente envolvidas e para escolas e organizações de educação complementar da região. A principal estratégia de divulgação e mobilização dos participantes foi através dos próprios educandos das instituições coorganizadoras.

Concomitantemente, também se definiu o formato do IV Seminário Teorias e Práticas Sociais com Crianças e Adolescentes, com a realização de uma mesa de abertura; a realização posterior de 04 (quatro) Rodas de Diálogo (devido ao número e à diversidade de temas abordados nos relatos apresentados) e o encerramento com uma mesa que sintetizaria as discussões e encaminhamentos das Rodas de Diálogo.

A quarta fase correspondeu ao desenvolvimento da proposta em si. Um novo encontro entre as instituições precedeu a semana. Nessa ocasião, foram definidos alguns detalhes como materiais necessários, equipe de apoio, lanche para os participantes. Foram também padronizados alguns aspectos pedagógicos: realização de uma roda/conversa inicial com os participantes de cada atividade para situá-los dentro da proposta geral da semana e da proposta específica daquela atividade e uma roda/conversa final para avaliar o desenvolvimento da atividade, as aprendizagens ocorridas e para reforçar as possibilidades de atividades do dia seguinte. Com os detalhes definidos, a semana de oficinas e o seminário transcorreram sem grandes imprevistos.

A quinta fase foi a avaliação, feita através de um encontro presencial e através de um questionário preenchido no encontro presencial ou encaminhado através de $e$-mail para os que não puderam comparecer. Desse encontro e das respostas aos questionários, surgiu como encaminhamento articular novas ações envolvendo as instituições participantes e outras potenciais, principalmente através de um momento de planejamento conjunto no início do ano de 2008.

\section{RESULTADOS}

Foram oferecidas 74 (setenta e quatro) oficinas e realizadas 68 (sessenta e oito) durante a Semana da Criança e do Adolescente: por uma Cidade Educadora. Participaram, em sua maioria, educandos vinculados ao Projeto Esporte Talento e à Associação Esporte Solidário, os quais trouxeram em alguns momentos amigos da comunidade local. Também participaram crianças e adolescentes do Projeto Vizinho Legal Cultura, da EMEF Brasil Japão, da EE João Cruz Costa, da Escola Munici- 
pal de Ensino Infantil Emir Macedo, do Circo-Escola São Remo e do CECCO Parque Previdência.

Crianças, adolescentes, jovens e adultos foram convidados a participar, vivenciar e discutir temas diversos: a cultura corporal, o esporte, o meio ambiente, as artes, a cultura de rua, etc; sob a perspectiva de direitos e deveres. A participação foi espontânea, sem necessidade de vinculação com nenhuma instituição de educação formal ou informal. A proposta desenvolveuse em espaços públicos da região do Butantã, estimulando a possibilidade de uso, a apropriação e a manutenção desses espaços pelos participantes.

A principal instituição pública envolvida foi a Universidade de São Paulo. A maioria das atividades ocorreu no Centro de Práticas Esportivas da Universidade de São Paulo, que é a unidade da Universidade que desenvolve o Projeto Esporte Talento. Além disso, houve o envolvimento de outro programa do CEPEUSP, o Grupo de Estudos do Futebol, que ofereceu 2 (duas) oficinas durante a semana. A Pró-Reitoria de Cultura e Extensão Universitária também apoiou com recursos do Fomento às Iniciativas de Cultura e Extensão (antigo Fundo de Cultura e Extensão Universitária), com a participação de educadoras e cedendo a sua sala de cinema - CINUSP - para uma atividade.

Além do CEPEUSP e do CINUSP, as oficinas ocorreram nos seguintes espaços: Campo de Futebol da São Remo, Circo-Escola São Remo, Parque Previdência, Parque Villa-Lobos, Praça do Balão (Jaguaré), Praça do Relógio, Praça Elis Regina, Praça Wilson Moreira da Costa, EMEF Brasil-Japão e EE João Cruz Costa.

Quantitativamente, o número de participantes ficou abaixo do esperado, mas a qualidade das atividades e do envolvimento dos participantes foi positiva e a mobilização e as questões despertadas nas instituições da região do Butantã foram significativas para refletir sobre o tema proposto.

O número e a diversidade das instituições proponentes de atividades foram além do esperado. A proposta, de uma forma prática, demonstrou uma consolidação local importante e um diálogo com a cidade em pleno processo de ascensão. As seguintes instituições ofereceram oficinas durante a semana: Agentes Comunitários de Saúde do Jd. São Remo, Associação Esporte Solidário, CECCO (Centro de Convivência e Cooperativa) Parque Previdência, Fundação Eprocad - Santana do Parnaíba, Fundação Projeto Travessia, Grupo de Estudo do Futebol - CEPEUSP, OBB (Outward Bound Brasil), Projeto Esporte Talento, Projeto Vizinho Legal Cultura, Pró-Reitoria de
Cultura e Extensão Universitária-USP, SESC — Programa Curumim, SESC Interlagos.

O IV Seminário Teorias e Práticas Sociais com Crianças e Adolescentes: por uma Cidade Educadora contou com a mesa de abertura "Por uma Cidade Educadora para as crianças e os adolescentes", desenvolvida pelos palestrantes: Prof. Dr. Paulo Padilha, do Instituto Paulo Freire; Prof. Dr. Nabil Bonduki, da Faculdade de Arquitetura e Urbanismo da USP; Sra. Natacha Costa, diretora da Associação Cidade Escola Aprendiz; Sr. Agnaldo dos Santos, do Instituto Pólis, que foi o mediador. No período da tarde ocorreram 4 (quatro) Rodas de Diálogo simultâneas: "A cidade e a juventude”; "A cidade e as ruas"; "A cidade e a cultura”; "A cidade e o esporte", com um total de 19 (dezenove) relatos apresentados e 0 posterior diálogo entre todos os participantes, a partir dos temas geradores (Cidade Educadora e o tema específico de cada roda), dos relatos apresentados e das experiências pessoais e institucionais de cada participante. Uma breve mesa final "Síntese das Rodas de Diálogo" encerrou o seminário e foi seguida do lançamento oficial da publicação do "III Seminário Teorias e Práticas Sociais com Crianças e Adolescentes: políticas públicas”, que também contou com o apoio do Fomento às Iniciativas de Cultura e Extensão da Pró-Reitoria de Cultura e Extensão Universitária da USP. Participaram do evento 101 (cento e uma) pessoas, com uma média de 20 (vinte) pessoas por roda de diálogo.

Assim como na Semana da Criança e do Adolescente, a diversidade e quantidade de instituições que apresentaram relatos foi significativa, inclusive com um relato proveniente de um projeto do Estado do Mato Grosso do Sul. Inscreveram relatos: CECCO (Centro de Convivência e Cooperativa) Parque Previdência, CEDECA Interlagos (Centro de Defesa dos Direitos da Criança e do Adolescente), Comunidade Pro Rei, CRAF (Centro de Referência Ação Família) Rio Pequeno, Finasa Esportes, OBB (Outward Bound Brasil), Projeto Quixote, Pró-Reitoria de Cultura e Extensão Universitária da USP, Projeto Córrego Bandeira, Projeto Esporte Talento, Projeto Vizinho Legal Cultura, Rotary Club SP Imigrantes, Secretaria Municipal de Esporte da cidade de São Paulo, SENAC Jabaquara, SESC Carmo — Programa Curumim, SESC Interlagos.

Portanto, conclui-se que os pontos fortes das duas etapas do evento foram: a mobilização e diversidade das instituições participantes; envolvimento dos participantes nas atividades (oficinas e rodas de diálogo); mobilização e participação espontânea de algu- 
mas pessoas da comunidade nas oficinas; utilização dos espaços públicos; processo coletivo de construção da proposta; realização de dois produtos (pré-publicação e DVD) para continuidade da discussão e possibilidade de novas propostas. Os pontos fracos foram: número de participantes em relação ao potencial e expectativa de participação - principalmente na Semana da Criança e do Adolescente; dificuldade de apropriação da proposta pelas crianças, adolescentes e instituições, em parte por falhas de estratégias de envolvimento e em parte pela dificuldade de alterar a rotina e abrir-se às novidades, como o uso de espaços públicos abertos.

Um dos principais encaminhamentos do evento em sua fase de avaliação - foi a realização de um encontro entre os participantes no início do ano seguinte, com o objetivo de planejar ações conjuntas. Vale ressaltar que esse encontro ocorreu e que deliberou por um maior engajamento das instituições nas redes sociais da região.

Dois grandes produtos foram elaborados, garantindo a disseminação do trabalho desenvolvido:

- Um DVD, com os principais momentos da Semana e do Seminário, entregue a todas as instituições coorganizadoras, a parceiros estratégicos e, no ano seguinte, a todos os participantes do "V Seminário Teorias e Práticas Sociais com Crianças e Adolescentes: o jovem em movimento na cidade";

- Uma pré-publicação, com o resumo de todas as oficinas e relatos, que foi entregue como parte da pasta a todos os participantes do seminário, permitindo uma boa perspectiva do que seria o evento e garantindo um material por escrito para o participante buscar referências e disseminar a participação na sua instituição.

\section{CONCLUSÕES}

O IV Seminário Teorias e Práticas Sociais com Crianças e Adolescentes: por uma cidade educadora cumpriu com os objetivos de sua origem e os específicos da edição. 0 tema escolhido - por uma cidade educadora - desperta muitas discussões, reflexões e possíveis ações. E podemos dizer que todos nós fazemos pequenas escolhas diárias que afetam os rumos de nossa cidade.

Estamos em uma época de transição e de rápidas mudanças. Por exemplo, os meios de comunicação globais promovem e popularizam novas atrações ao mesmo tempo em que tornam possível a eliminação das interações "cara a cara” (ZUKIN, 2008).
A partir disso podemos nos questionar se os espaços públicos serão os de convivência de um futuro próximo ou se as pessoas se encontrarão predominantemente em espaços virtuais. E, se assim for, quais serão as consequências?

Nossa experiência tem apontado que o envolvimento coletivo e a co-responsabilização tornam-se escassos diante do modo de vida atual, até mesmo para quem habita um espaço comum. A realização da Semana da Criança e do Adolescente e do IV Seminário Teorias e Práticas Sociais com Crianças e Adolescentes mostrou que essa interação mais intensa e co-responsável é desejada pelas pessoas e instituições. Ao mesmo tempo, evidencia que só é possível se bem estimulada por ambos na sua disposição de recriar os espaços de encontro. Por fim, requer um olhar mais atento às possibilidades de articulação, mais voltado para o coletivo e cada vez mais renovado no exercício do papel de todos de promover educação e cidadania.

Enquanto universidade, temos o compromisso de abrir espaços de discussão. E foi isso o que propusemos com a realização do IV Seminário Teorias e Práticas Sociais com Crianças e Adolescentes: por uma cidade educadora.

\section{REFERÊNCIAS BIBLIOGRÁFICAS}

AICE. Declaração de Barcelona. In: Carta das Cidades Educadoras. Barcelona, 1990. Disponível em: <http://www.quintacidade.com/wp-content/uploads/2008/04/cartacidadeseducadoras.pdf>. Acesso em: 08 abr. 2009.

BRARDA, A.; RÍOS, G. Argumentos e estratégias para a construção da Cidade Educadora. In: GADOTTI, M.; PADILHA, P.; CABEZUDO, A. (Org.) Cidade educadora: princípios e experiência. São Paulo: Cortez Editora, 2004.

BRASIL. Estatuto da Criança e do Adolescente: Lei no 8.069, de 13 de julho de 1990. Brasília: Secretaria de Estado dos Direitos Humanos, Departamento da Criança e do Adolescente, 2002.

CABEZUDO, A. Cidade Educadora: uma proposta para os governos locais. In: GADOTTI, M.; PADILHA, P.; CABEZUDO, A. (Org.) Cidade educadora: princípios e experiência. São Paulo: Cortez Editora, 2004.

OLIVEIRA, C. O ambiente urbano e a formação da criança. São Paulo: Aleph, 2004.

ZUKIN, S. Cultura urbana: em busca de la autenticidad. In: BOSCH, E. (Ed.) Educación y vida urbana: 20 años de Ciudades Educadoras. Barcelona: Santillana, 2008. 